\title{
Prevalence of Molar Incisor Hypomineralisation Among School Children in Kavre
}

\section{Shrestha R, Upadhaya S, Bajracharya M}

\author{
Department of Conservative Dentistry and \\ Endodontics \\ Dhulikhel Hospital - Kathmandu University Hospital \\ Kathmandu University School of Medical Sciences \\ Dhulikhel, Kavre, Nepal
}

\section{Corresponding author}

Reetu Shrestha

Department of Conservative Dentistry and Endodontics

Dhulikhel Hospital - Kathmandu University Hospital Kathmandu University School of Medical Sciences Dhulikhel, Kavre, Nepal

Email: rreetuz@gmail.com

\section{Citation}

Shrestha R, Upadhaya S, Bajracharya M. Prevalence of Molar Incisor Hypomineralisation Among School Children in Kavre. Kathmandu Univ Med J 2014;45(1):38-42.

\section{ABSTRACT}

\section{Background}

Molar incisor hypomineralisation is defined as the hypomineralisation of systemic origin of one to four permanent first molars, and frequently associated with affected incisors. Till date, there is no data available on molar incisor hypomineralisation in any parts of Nepal.

\section{Objective}

To determine the prevalence and characteristics of Molar incisor hypomineralisation in 7 to 12 years old school children of Kavre.

\section{Method}

A total of 749 school children of age 7 to 12 years from four different randomly selected schools with at least one of the first permanent molars fully or partially erupted were evaluated using European Academy of Paediatric Dentistry criteria for molar incisor hypomineralisation. The examinations were conducted at respective schools by a single calibrated examiner.

\section{Result}

Molar incisor hypomineralisation was present in $13.7 \%$ of children. No gender differences were found.The mild type of defect (without structural loss of tooth) was the most prevalent type of molar incisor hypomineralisation with white/creamy demarcated opacities more frequent than yellow/brown demarcated opacities. Post eruptive breakdown was more in boys than in girls and this difference was statistically significant $(p<0.05)$. Also, maxillary molars were affected more than mandibular molars and this difference was also statistically significant $(p<0.05)$.

\section{Conclusion}

The prevalence of molar incisor hypomineralisation in Kavre was 13.7\%.Demarcated opacities were more prevalent than breakdown. The hypomineralised defect was more prevalent in maxillary teeth than in mandibular teeth. The severity of defect increased with age and there was no difference in prevalence between girls and boys.

\section{KEY WORDS}

Molar incisor hypomineralisation, post eruptive breakdown

\section{INTRODUCTION}

The term molar incisor hypomineralisation (MIH) was suggested by Weerheijm et al in 2001 and he defined it as hypomineralisation of systemic origin of one to four permanent first molars, frequently associated with affected incisors. ${ }^{1}$

Clinically the severity of the MIH lesion may vary from white to yellow/ brownish demarcated opacities to structural loss under masticatory forces. ${ }^{2}$ This post eruptive breakdown
(PEB) exposes the dentin which can be extremely sensitive and due to this, children cannot carry out the oral hygiene effectively and makes the tooth vulnerable to rapidly progressing caries. Children with the condition are also at risk of developing dental phobias and presenting behavior management problems. ${ }^{3}$

A variety of causes have been described for $\mathrm{MIH}$, both environmental and genetic. ${ }^{4,5} \mathrm{MIH}$ may be acquired as a 
result of prenatal, perinatal and post natal illness, low birth weight, antibiotic consumption and toxins from breast feeding. The relevance of each event is difficult to establish as many of those events can happen more than once during early childhood. ${ }^{6}$

The prevalence of $\mathrm{MIH}$ varies considerably throughout the world ranging from $2.4 \%$ in China to $40.2 \%$ in Brazil. ${ }^{7,8}$ Majority of the study are being done in Europe, few in China, Libya, Australia, Kenya and Brazil and none in Nepal. ${ }^{5-14}$

Therefore, the purpose of the study was to determine the prevalence of $\mathrm{MIH}$ in 7 to 12 years children in Kavre, Nepal. Other aim is to determine the characteristics of $\mathrm{MIH}$ in the population.

\section{METHODS}

A descriptive cross-sectional study was done in four different schools of Kavre district from January 10 to February 10, 2014. The schools were randomly selected. All the students who were 7 to 12 years old were examined and the total sample was 749. The principal, parents/ guardians and the students who participated in the study were informed about the study and their written consent was taken.

The research was conducted with approval of Kathmandu University School of Medical Sciences Institutional Review Committee (KUSMS/IRC).

The inclusion criteria were 7 to 12 years children with at least one of their permanent first molars and or incisors are fully or partially erupted (minimum $1 / 3^{\text {rd }}$ of clinical crown height). Children with generalized developmental defect such as amelogenesis imperfecta were excluded.

The natural level of fluoride in all the four community water was below $0.25 \mathrm{ppm}$. This data was obtained from Department of Community Programs, Dhulikhel hospital. This data collection by Department of Community Programs was done for a project on 'Fluoride mouth rinsing program in Nepal' conducted in the year 2013 (ongoing research).

Before initiation of the study, a calibration exercise was carried out for the examiner with the help of the Paediatric dentist. A set of 20 photographs including both $\mathrm{MIH}$ and other enamel developmental defects was used to calibrate the examiner and the exercise was repeated after one month. Using Kappa test, inter- and intra- examiner agreement for $\mathrm{MIH}$ were reported as 0.78 and 0.88 respectively.

Dental examinations were performed in the classroom using a mouth mirror and explorer under a headlight. Teeth were wiped with gauze when necessary to remove plaque or the food accumulations. Surfaces that were examined were the buccal, lingual/ palatal and occlusal surface of permanent first molars and labial surfaces of upper and lower incisors.

All data were collected in a record chart designed for this study in which European Academy of Paediatric Dentistry (EAPD) recommendation criteria was used for scoring $\mathrm{MIH}$ which included the codes form 0 to 10 (Table 1$) \cdot{ }^{15}$ During the analysis we supposed the unerupted tooth also did not have $\mathrm{MIH}$; thus code 6 was also considered as code 0 . Also, both the white/creamy demarcated opacities, with PEB and yellow/brown demarcated opacities, with PEB were included in the group of teeth with PEB. Tooth with $\mathrm{PEB}$ was considered having more severe $\mathrm{MIH}$ than with demarcated opacities.

Table 1. Criteria for scoring MIH according to European Academy of Paediatric Dentistry.

\begin{tabular}{|c|c|}
\hline Code & Criteria \\
\hline 0 & Enamel defect free \\
\hline 1 & White/creamy demarcated opacities, no PEB \\
\hline $1 \mathrm{a}$ & White/creamy demarcated opacities, with PEB \\
\hline 2 & Yellow/brown demarcated opacities, no PEB \\
\hline $2 a$ & Yellow/brown demarcated opacities, with PEB \\
\hline 3 & Atypical restoration \\
\hline 4 & Missing because of MIH \\
\hline 5 & $\begin{array}{l}\text { Partially erupted(i.e., less than } 1 / 3 \text { of the crown } \\
\text { height) with evidence of } \mathrm{MIH}\end{array}$ \\
\hline 6 & $\begin{array}{l}\text { Unerupted or partially erupted with no evidence of } \\
\text { MIH }\end{array}$ \\
\hline 7 & Diffuse opacities (not MIH) \\
\hline 8 & Hypoplasia (not MIH) \\
\hline 9 & $\begin{array}{l}\text { Combined lesion (diffuse opacities/ hypoplasia with } \\
\mathrm{MIH} \text { ) }\end{array}$ \\
\hline 10 & Demarcated opacities in incisors only \\
\hline
\end{tabular}

The collected data were analysed using the SPSS package version 17.0 (SPSS Inc, Chicago, IL, USA). A descriptive analysis of the prevalence and distribution of the clinical recordings were performed. Fischer's exact test and chi square test were applied. A p value $<0.05$ was considered as statistically significant.

\section{RESULTS}

Among the 749 accessed children of age group 7 to 12 years, two were excluded due to presence of amelogenesis imperfecta. Therefore, a total of 747 children were included in the study.

The prevalence of $\mathrm{MIH}$ was found to be $13.7 \%$ (102 children). The distribution pattern and prevalence of $\mathrm{MIH}$ are summarized in Table 2.

\begin{tabular}{|c|c|c|c|}
\hline \multirow[t]{2}{*}{ Affected } & \multicolumn{2}{|c|}{ Gender } & \multirow[t]{2}{*}{ Total } \\
\hline & Boys & Girls & \\
\hline *Only molars & 4 & 11 & 14 \\
\hline *Molars and incisors & 50 & 37 & 87 \\
\hline +Total MIH & 54 & 48 & 102 \\
\hline Total non-MIH & 288 & 357 & 645 \\
\hline
\end{tabular}


Involvement of molar without involvement of incisor(s) was more prevalent in girls and the combined involvement of molar and incisor(s) was more prevalent in boys. This difference was statistically significant $(p<0.05)$ (Table 2$)$. Although boys were more affected than girls with $\mathrm{MIH}$, there was no statistically significant difference $(p>0.05)$ (Table 2).

The involvement of incisor was increased with the increase in number of affected molar and this difference was statistically significant $(p<0.05)$ (Table 3 ).

Table 3. Distribution pattern of affected first molars and incisors.

\begin{tabular}{lccccccccccc|}
$\begin{array}{l}\text { Number } \\
\text { of molar } \\
\text { involved }\end{array}$ & $\mathbf{1}$ & $\mathbf{1}$ & $\mathbf{1}$ & $\mathbf{2}$ & $\mathbf{3}$ & $\mathbf{4}$ & $\mathbf{5}$ & $\mathbf{6}$ & $\mathbf{7}$ & $\mathbf{8}$ & \\
\hline 1 & 1 & 0 & 2 & 0 & 0 & 0 & 0 & 0 & 2 & 5 \\
\hline 2 & 1 & 1 & 0 & 3 & 1 & 0 & 2 & 2 & 0 & 10 \\
\hline 3 & 0 & 2 & 3 & 1 & 1 & 1 & 3 & 0 & 0 & 11 \\
\hline 4 & 14 & 1 & 8 & 5 & 19 & 6 & 12 & 0 & 11 & 76 \\
\hline $\begin{array}{l}\text { Total } \\
\text { Pearson's chi square test, } \mathrm{p}=0.001\end{array}$ & 16 & 4 & 13 & 9 & 21 & 7 & 17 & 2 & 13 & 102 \\
\hline
\end{tabular}

The severity of the defect varied from demarcated enamel opacities to structural loss of tooth i.e. the post eruption breakdown (PEB).The mild type of defect (without structural loss of tooth) was the most prevalent type of $\mathrm{MIH}$ with white/creamy demarcated opacities more frequent than yellow/brown demarcated opacities (Table 4).

Table 4. Distribution of molar incisor hypomineralisation defect by its type.

\begin{tabular}{lcccc|}
\hline Defect type & $\begin{array}{c}\text { No of mo- } \\
\text { lars }\end{array}$ & $\%$ & $\begin{array}{c}\text { No of inci- } \\
\text { sors }\end{array}$ & $\%$ \\
\hline $\begin{array}{l}\text { No defect } \\
\text { White/creamy de- }\end{array}$ & 161 & 5.38 & 325 & 5.43 \\
$\begin{array}{l}\text { marcated opacities, } \\
\text { no PEB }\end{array}$ & 121 & 4.04 & 23 & 0.38 \\
$\begin{array}{l}\text { Yellow/brown de- } \\
\text { marcated opacities, } \\
\text { no PEB }\end{array}$ & 75 & 2.51 & 19 & 0.31 \\
$\begin{array}{l}\text { Demarcated opacities, } \\
\text { with PEB }\end{array}$ & 4 & 0.13 & 42 & 0.70 \\
\hline $\begin{array}{l}\text { Partially erupted with } \\
\text { evidence of MIH }\end{array}$ & 2988 & 100 & 5976 & 100 \\
\hline \begin{tabular}{l} 
Total \\
\hline
\end{tabular} & & & & \\
\hline
\end{tabular}

The post eruptive breakdown was more in boys than in girls and this difference was statistically significant $(p<0.05)$ (Table 5). Furthermore, as the age of the children increased, more was the number of teeth with PEB observed. This difference was also statistically significant $(p<0.05)$ (Table $6)$.

Among the molars involved by $\mathrm{MIH}(408), 79.3 \%$ (79) had PEB whereas only $7.4 \%$ (61 out of 816 ) of incisors had PEB.

Maxillary molars were affected more than mandibular molars by $\mathrm{MIH}$ and this difference was also statistically significant $(p<0.05)$ (Table 7).
Table 5. Distribution of post eruptive breakdown (PEB) by gender.

\begin{tabular}{|lccc|}
\hline Sex & PEB present & PEB absent & Total \\
\hline Girls & 25 & 29 & 54 \\
Boys & 31 & 17 & 48 \\
Total & 56 & 46 & 102 \\
\hline
\end{tabular}

Pearson's chi square test, $p=0.011$

Table 6. Distribution of post eruptive breakdown (PEB) with age.

\begin{tabular}{|cccc|}
\hline Age & $\begin{array}{c}\text { No } \\
\text { of children } \\
\text { with PEB }\end{array}$ & $\begin{array}{c}\text { No of children } \\
\text { without PEB }\end{array}$ & Total \\
\hline 7 & 4 & 5 & 9 \\
\hline 8 & 6 & 7 & 13 \\
\hline 9 & 8 & 11 & 19 \\
\hline 10 & 11 & 9 & 20 \\
\hline 11 & 12 & 9 & 21 \\
\hline 12 & 15 & 5 & 20 \\
\hline Total & 46 & 46 & 102 \\
\hline
\end{tabular}

Pearson's chi square test, $p=0.006$

Table 7. Distribution of MIH in maxillary and mandibular arch.

\begin{tabular}{|c|c|c|c|c|c|}
\hline \multicolumn{6}{|c|}{ No of Mandibular Molars } \\
\hline \multirow{5}{*}{ 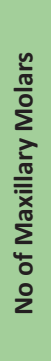 } & & No defect & $\begin{array}{l}\text { Defect in } \\
\text { one molar }\end{array}$ & $\begin{array}{l}\text { Defect in } \\
\text { both mo- } \\
\text { lars }\end{array}$ & Total \\
\hline & No defect & 0 & 0 & 4 & 4 \\
\hline & $\begin{array}{l}\text { Defect in one } \\
\text { molar }\end{array}$ & 4 & 4 & 7 & 17 \\
\hline & $\begin{array}{l}\text { Defect in both } \\
\text { molars }\end{array}$ & 2 & 6 & 75 & 81 \\
\hline & Total & 6 & 10 & 86 & 102 \\
\hline
\end{tabular}

Pearson's chi square test, $p=0.00$

\section{DISCUSSION}

This study shows the prevalence of $\mathrm{MIH}$ among school children in Kavre district of Nepal to be $13.7 \%$. This was greater than that observed in Chinese children and comparable to data obtained from Italy and Bosnia and lower than that reported from Swedish and Danish children. ${ }^{7,10,16-18}$ The wide range of prevalence rate in other study could be related to difference in ethnic and age group and the different diagnostic criteria involved. The present study used the MIH diagnosis criteria established by EAPD in 2003 and single calibrated examiner was involved during the examination to avoid inter-examiner bias. ${ }^{15}$

The children of age group of 7 to 12 years were selected because at this age at least one of the first molar would have erupted and also the risk of defect in the enamel being masked by large carious region in later age would be minimized. As the unerupted teeth were considered to have no defect, due to difficulty in prediction, this might have however have caused the underestimation of the prevalence in the current population.

In this study finding, there were no difference in the number of girls and boys with $\mathrm{MIH}$ which is in agreement with other authors. ${ }^{10,16,17,19,20}$ The prevalence of combined 
molar and incisor defect were more than defect only in molar. The relationship between the number of affected molar and number of incisor involved by the defect was also in agreement with other reports but in the study done by Kotsanos et al this relation was not found..$^{10,11,21}$ This may be because of small sample size in their study.

It was confirmed in previous studies that optimal concentration of fluoride in drinking water (0.7-1.2ppm) was not implicated in etiology of $\mathrm{MIH}^{22,23}$ The fluoride of natural drinking water content in all four communities was less than $0.25 \mathrm{ppm}$ which was less than the optimal concentration. But, it is beyond the scope of this study to find the relation between amount of fluoride in drinking water and occurrence of $\mathrm{MIH}$ and further research is required on this matter.

The varying degree of enamel defect in the permanent first molars in individual children suggests that not all the teeth are equally sensitive to developmental disturbances. The severity of the defect as measured by PEB increased along with the age of the child which could suggest that the hypomineralised lesion are not static i.e. as the child grows, the mild defect can worsen leading to clinical detection of structural loss. Also, as in other studies, boys had significantly more number of teeth with PEB than girls. ${ }^{6,8}$

\section{REFERENCES}

1. Weerheijm KL, Jälevik B, Alalususua S. Molar incisor hypomineralization. Caries Res. 2001;35(5):390-1.

2. Weerheijm KL. Molar incisor hypomineralization(MIH): clinical presentation, aetiology and management. Dent Update. 2004;31(1):912.

3. Jälevik B, Klingberg GA. Dental treatment, dental fear and behaviour management problems in children with severe enamel hypomineralisation of their permanent first molars. Int J Paediatr Dent. 2002;12(1):24-32.

4. William V, Messer LB, Burrow MF. Molar-incisor-hypomineralisation: Review and recommendations for clinical management. Pediatr Dent. 2006;28(3):224-32.

5. Brook AH, Smith JM. Aetiology of developmental defects of enamel: a prevalence and family study in East London, UK. Connect Tissue Res. 1998;39(1-3):151-6.

6. Costa-Silva CMD, Jeremias F, DeSouza JF, Cordeiro RCL, Pinto LS, Cristina A. Molar incisor hypomineralization: prevalence, severity and clinical consequences in Brazilian children. Int $J$ Pediatr Dent. 2010;20(6):426-34.

7. Cho SY, Ki Y, Chu V. Molar incisor hypomineralization in Hong Kong Chinese children. Int J Paediatr Dent. 2008;18(5):348-52.

8. Soviero V, Haubek D, Trindade C, Matta T, Poulsen S. Prevalence and distribution of demarcated opacities and their squeals in permanent first molars and incisors in 7 to 13-year-old Brazilian children. ActaOdontol Scand. 2009;67(3):170-5.

9. Wogelius P, Haubek D, Poulsen S. Prevalence and distribution of demarcated opacities in permanent 1st molars and incisors in 6 to 8-year-old Danish children. ActaOdontol Scand. 2008;66(1):58 -64.

10. Jälevik B, Klingberg G, Barregard L, Noren JG. The prevalence of demarcated opacities in permanent first molars in a group of Swedish children. ActaOdontol Scand. 2001;59(5):255-60.
The demarcated opacities were the most frequently found type of MIH in our study and the white/creamy demarcated opacities were more common than yellow/brown ones. It is stated that the yellow/brown opacities have greater hypomineralised tissue porosities and less strong thus having greater chance of post eruptive breakdown..$^{24,25}$

In our study we found that maxillary molars were affected significantly more than mandibular molars with hypomineralised defects which is similar to as reported by Leppäniemiet al. ${ }^{21}$

\section{CONCLUSION}

The prevalence of $\mathrm{MIH}$ in school children of Kavre was found to be $13.7 \%$. The hypomineralized defect was more prevalent in maxillary teeth than in mandibular teeth. The severity of defect increased with age and there was no difference in prevalence between girls and boys. Further studies are required to determine the cause of $\mathrm{MIH}$.

\section{ACKNOWLEDGEMENT}

We would like to thank Department of Community Programs, Dhulikhel hospital for their immense help and support to conduct this study.
11. Preusser SE, Ferring V, Wleklinski C, Wetzel WE. Prevalence and severity of molar incisor hypomin eralization in a region of Germany -a brief communication. J Public Health Dent. 2007;67(3):148-50.

12. Feita $\mathrm{D}$, Ali A, Alalususua S. Molar- incisor hypomineralization (MIH) in a group of school aged children in Benghazi, Libya. Eur Arch Paediatr Dent. 2006;7(2):92-5.

13. Arrow P. Prevalence of developmental enamel defects of the first permanent molars among school children in Western Australia. Aus Dent J. 2008;53(3):250-9.

14. Kemoli AM. Prevalence of molar incisor hypomineralization in six to eight years olds in two rural divisions in Kenya. East Afr Med J. 2008;85(10):514-9.

15. Weerheijm K, Duggal M, Mejáre I. Judgement criteria for molar-incisor hypomineralisation (MIH) in epidemiologic studies: a summary of the European meeting on MIH held in Athens, 2003. Eur J Paediatr Dent. 2003;4(3):110-3.

16. Calderara PC, Gerthoux PM, Mocarelli P. The prevalence of Molarincisor-hypomineralization in a group of Italian school children. Eur J Paediatr Dent. 2005;6(2):79-83.

17. Muratbegovic A, Markovic N, Ganibegovic Selimovie M. Molarincisor-hypomineralization in Bosnia and Hezegovina: aetiology and clinical consequences in medium caries activity population. Eur $J$ Paediatr Dent. 2007;8(4):189-94.

18. Weerheijm KL, Mejare I. Molar-incisor-hypomineralization: a questionnaire inventory of its occurrence in member countries of European Academy of Paediatric Dentistry (EAPD). Int J Paediatr. 2003;13(6):411-16.

19. Martınez Gomez TP, Guinot Jimeno F, Bellet Dalmau LJ, Giner Tarrida L. Prevalence of molar-incisor hypomineralisation observed using transillumination in a group of children from Barcelona (Spain). IntJ Paediatr Dent. 2012;22(2):100-9. 
20. Leppäniemi A, Lukinmaa PL, Alaluusua S. Nonfluoride hypomineralizations in the permanent first molars and their impact on the treatment need. Caries Res. 2001;35(1):36-40.

21. Kotsanos N, Kaklamanos EG, Arapostathis K. Treatment management of first permanent molars in children with molar incisor hypomineralisation. Eur J Paediatr Dent. 2005;6(4):179-84.

22. Balmer RC, Laskey D, Mahoney E, Toumba KJ. Prevalence of enamel defects and MIH in non-fluoridated and fluoridated communities. Eur J Paediatr Dent. 2005;6(4):209-12.
23. Koch G. Prevalence of enamel mineralization disturbances in an area with 1-1.2 ppm F in drinking water. Review and summary of a report published in Sweden in 1981. Eur J Paediatr Dent. 2003;4(3):127-28.

24. Lygidakis NA, Dimou G, Briseniou E. Molar-Incisor-Hypomineralisation (MIH). Retrospective clinical study in Greek children. I. Prevalence and defect characteristics. Eur Arch Paediatr Dent. 2008;9(4):200-6.

25. Mangum JE, Crombie FA, Kilpatrick N, Manton DJ, Hubbard MJ. Surface integrity governs the proteome of hypomineralized enamel. $J$ Dent Res. 2010;89(10):1160-5. 